\title{
Homophily Effect of Academic Achievement on Adolescent Friendship Network Evolution
}

\author{
Chyi-In $\mathrm{Wu}^{1}$, and Hsieh-Hua Yang ${ }^{2, *}$ \\ ${ }^{1}$ Institute of Sociology, Academia Sinica, 11529 Taipei, Taiwan \\ ${ }^{2}$ Department of Health Care Administration, Oriental Institute of Technology, 22061 New Taipei City, Taiwan
}

\begin{abstract}
The objective is testing the homophily effect of academic achievement on adolescent friendship network evolution. There were 93 boys and 82 girls of high school students participating in this study. Panel data was collected 10 waves during 3 semesters from Sep. 2008 to Jan. 2010. The students were asked to nominate up to 16 intimate classmates. Academic achievement of computer science, mathematics, Chinese, and English was measured in the beginning of 3 semesters. The model was constructed by the program SIENA. The results demonstrated the homophily effect of perceived academic achievement was significant for computer science at the first semester, for mathematics and English at the second semester, and for Chinese at the third semester.
\end{abstract}

\section{Introduction}

The importance of peer influence has been confirmed by many researchers. The process of influence is either by homophily principle or assimilation principle. Homophily principle was proposed by [1] to explain the network autocorrelation, which stands for the argument that it is easier or more rewarding for an actor to interact with a similar other than with a dissimilar other. An alternative explanation of the same phenomenon is the assimilation principle according to which network actors adapt their own individual characteristics to match those of their social neighborhood $[2,3]$.

Friendship plays a distinct role in adolescent development. It provides social support, promoting social skills, and also feeling of belongingness. It represents unique relationships that differ from other relationships. Friendship stability may have impact on adolescent adjustment or reinforcing behaviour patterns. Friendship network formation is an evolution process. It is likely to adapt to an individual's changing needs and goals. Some friendships are stable and last for a long time, some end temporarily or permanently after several days, and some others are newly-formed. Many theories are applied to explain the mechanism of social network evolution and behaviors. Social comparison theory [4] holds that people have a drive to evaluate his abilities by comparison with the abilities of others. And if this evaluation is possible with others who are close enough, then there should be some attraction to groups where others are relatively close with respect to abilities. Social learning theory [5] proposes that individuals' behaviors may arise and be reinforced through observing and imitating others, including peers. Therefore, individual interaction with peers, social support from peers and their understanding of situations are important factors which have effect on individual learning outcome.

Many researchers studied the effect of social context on educational outcomes. Daw, Guo, and Harris [6] use a regression model to test the shared and nonshared environment exert important influences on the academic achievement. Levy-Tossman, Kaplan, \& Assor [7] find the connection between academic motivation and social relationships. Frank et al. [8] agree on the importance of peer influences and find that girls are highly responsive to the social norms in their local positions. Hasan and Bagde [9] found that peer effects are a consequential determinant of academic achievement.

Friendship network formation is an evolution process. During the evolution process, strangers are converted to acquaintances and acquaintances to friends. van Duijn et al. [10] developed a theory to explain how changes in the network structure. The theory posits that proximity plays a dominant role in the formation of networks, visible similarity plays a role in the beginning of the friendship development process, and invisible similarity will have effect at later stages of the friendship development. A friendship is more likely to be continued if each individual perceives the other as similar in a variety of ways. We argue that the similarity of academic achievement has effect on friendship network evolution. And the research questions are whether the similarity of academic performance has effect on friendship network evolution, and at what stages which subject is important.

In Taiwan's education system, the junior high school students' basic competence test (BCT) has 5 components: English, mathematics, Chinese, natural sciences, and social sciences. The senior high school students' subject

Corresponding author: yansnow@gmail.com 
competency test (SCT) covers English, Chinese, mathematics, the natural sciences and humanities. Both BCT and SCT have 3 subjects, English, Chinese, and mathematics. In this study, these 3 subjects and computer science were evaluated as academic performance.

\section{Method}

\subsection{Participants}

Data were from the project "Luminous Shine and Dark Shadow: The Duality of Late Adolescents to Early Adults' Friendship Networks" sponsored by the Academia Sinica in Taiwan. In this study, the participants were 175 high school students of 93 boys and 82 girls.

\subsection{Measurement}

Panel data was collected 10 waves during 3 semesters from Sep. 2008 to Jan. 2010. Sociometric data were collected by having each student nominate up to 16 intimate classmates.

Academic performance of computer science, mathematics, Chinese, and English was measured in the beginning of 3 semesters, namely at wave 1, 5, and 8 . Academic achievement was measured by asking the student if his/her performance was better than others.

\subsection{Data analysis}

The program SIENA (Simulation Investigation for Empirical Network Analysis) was applied to estimate the models for the evolution of social networks according to the dynamic actor-oriented model of Snijders [11, 12]. For the estimation, sociometric data was transformed into adjacency matrices. The academic performance was coded as 1 if it was worse than others, 2 if it was the same as others, and 3 if it was better than others. Boy was coded as 1 and girl as 2 .

The actor-oriented model [13] assumes that the network $\mathrm{X}(t)$ is evolving in continuous time, although being observed only at the discrete moments $\mathrm{t}_{m}, \mathrm{~m}=1, \ldots$, $M$. $M$ is the number of repeated observations. This actor orientation means that, for each change in the network, the perspective is taken of the actor whose tie is changing. It is assumed the actor $\mathrm{i}$ controls the set of outgoing tie variables $(\mathrm{X} i 1, . ., \mathrm{X} i \mathrm{~g})$, collected in the ith row of the adjacency matrix. The network changes only by one tie at a time. The moment when actor $i$ changes one of his ties can depend on the network structure and on attributes represented by observed covariates. The "moment when" is stochastically determined in the model by the rate function, and "the particular change to make" by the objective function and the gratification function.

In the study, the evolution model components include density, reciprocity, transitivity, gender similarity, and similarities of perceived academic performance. Density effect is defined as the number of outgoing ties.
Reciprocity effect is defined the number of reciprocated ties. A transitive triplet effect is defined by the number of transitive patterns in $i^{\prime} s$ relations of actors $(j, h)$ (an ordered pairs of actors to both of whom $i$ is tied, while also $j$ is tied to $h$ ) for which $i \rightarrow j \rightarrow h$ and also $i \rightarrow h$.

The program can estimate all possible effects simultaneously, and is suitable to test our hypotheses. The SIENA program is included in the StOCNET system, and can be downloaded from http://stat.gamma.rug.n1/stocnet/ [14].

\section{Results}

\subsection{Description of participants}

The analyses were run on the 175 students that were present at all ten measurement points. The participants' perceived academic achievement of computer science, mathematics, Chinese, and English was analysed for 3 observations. The result, as table 1, 2, and 3, showed that the perceived performance of computer science had no gender difference, while the perceived performance of mathematics and English had gender difference at all observations. And for the subject of Chinese, there was gender difference at the 2nd and 3rd semesters.

For mathematics, there were more boys who perceived their performance were better than others. For Chinese, there were more girls who perceived their performance were better than others. For English, there were more girls who perceived their performance were better than others.

Table 1. Academic achievement at $1^{\text {st }}$ semester

\begin{tabular}{|l|c|c|c|c|c|c|}
\hline Variable & \multicolumn{2}{|c|}{$\frac{\text { Boys }}{\mathrm{N} \%}$} & \multicolumn{2}{c|}{$\frac{\text { Girls }}{\mathrm{N}} \%$} & $\begin{array}{c}\text { Chi- } \\
\text { square }\end{array}$ & $\mathrm{p}$ \\
\hline \multicolumn{2}{|c|}{ Computer science } & & & & 0.25 & 0.883 \\
\hline 1 & 28 & 30.1 & 24 & 29.3 & & \\
\hline 2 & 41 & 44.1 & 39 & 47.6 & & \\
\hline 3 & 24 & 25.8 & 19 & 23.2 & & \\
\hline Mathematics & & & & & 17.12 & $<.001$ \\
\hline 1 & 35 & 37.6 & 48 & 58.5 & & \\
\hline 2 & 21 & 22.6 & 24 & 29.3 & & \\
\hline 3 & 37 & 39.8 & 10 & 12.2 & & \\
\hline Chinese & & & & & 5.98 & 0.050 \\
\hline 1 & 35 & 37.6 & 17 & 20.7 & & \\
\hline 2 & 27 & 29.0 & 31 & 37.8 & & \\
\hline 3 & 31 & 33.3 & 34 & 41.5 & & \\
\hline English & & & & & 6.32 & 0.043 \\
\hline 1 & 42 & 45.2 & 22 & 26.8 & & \\
\hline 2 & 24 & 25.8 & 28 & 34.1 & & \\
\hline 3 & 27 & 29.0 & 32 & 39.0 & & \\
\hline
\end{tabular}


Table 2. Academic achievement at $2^{\text {nd }}$ semester

\begin{tabular}{|c|c|c|c|c|c|c|}
\hline \multirow[t]{2}{*}{ Variable } & \multicolumn{2}{|c|}{ Boys } & \multicolumn{2}{|c|}{ Girls } & \multirow{2}{*}{$\begin{array}{l}\text { Chi- } \\
\text { square }\end{array}$} & \multirow[t]{2}{*}{$\mathrm{p}$} \\
\hline & & $\%$ & & $\%$ & & \\
\hline \multicolumn{3}{|c|}{ Computer science } & & & 4.08 & 0.130 \\
\hline 1 & 28 & 30.1 & 19 & 23.2 & & \\
\hline 2 & 38 & 40.9 & 46 & 56.1 & & \\
\hline 3 & 27 & 29.0 & 17 & 20.7 & & \\
\hline Mathematics & & & & & 6.88 & 0.032 \\
\hline 1 & 40 & 43.0 & 50 & 61.0 & & \\
\hline 2 & 23 & 24.7 & 18 & 22.0 & & \\
\hline 3 & 30 & 32.3 & 14 & 17.1 & & \\
\hline Chinese & & & & & 6.07 & 0.048 \\
\hline 1 & 31 & 33.3 & 14 & 17.1 & & \\
\hline 2 & 32 & 34.4 & 34 & 41.5 & & \\
\hline 3 & 30 & 32.3 & 34 & 41.5 & & \\
\hline English & & & & & 14.13 & 0.001 \\
\hline 1 & 40 & 43.0 & 18 & 22.0 & & \\
\hline 2 & 33 & 35.5 & 26 & 31.7 & & \\
\hline 3 & 20 & 21.5 & 38 & 46.3 & & \\
\hline
\end{tabular}

Table 3. Academic achievement at $3^{\text {rd }}$ semester

\begin{tabular}{|c|c|c|c|c|c|c|}
\hline \multirow[t]{2}{*}{ Variable } & \multicolumn{2}{|c|}{ Boys } & \multicolumn{2}{|c|}{ Girls } & \multirow{2}{*}{$\begin{array}{c}\text { Chi- } \\
\text { square }\end{array}$} & \multirow[t]{2}{*}{$\mathrm{p}$} \\
\hline & & $\%$ & $\mathrm{~N}$ & $\%$ & & \\
\hline \multicolumn{3}{|c|}{ Computer science } & & & 3.51 & 0.173 \\
\hline 1 & 31 & 33.3 & 23 & 28.0 & & \\
\hline 2 & 36 & 38.7 & 43 & 52.4 & & \\
\hline 3 & 26 & 28.0 & 16 & 19.5 & & \\
\hline Mathematics & & & & & 19.36 & $<0.001$ \\
\hline 1 & 33 & 35.5 & 53 & 64.6 & & \\
\hline 2 & 20 & 21.5 & 17 & 20.7 & & \\
\hline 3 & 40 & 43.0 & 12 & 14.6 & & \\
\hline Chinese & & & & & 11.66 & 0.003 \\
\hline 1 & 31 & 33.3 & 12 & 14.6 & & \\
\hline 2 & 33 & 35.5 & 26 & 31.7 & & \\
\hline 3 & 29 & 31.2 & 44 & 53.7 & & \\
\hline English & & & & & 12.84 & 0.002 \\
\hline 1 & 39 & 41.9 & 27 & 32.9 & & \\
\hline 2 & 33 & 35.5 & 16 & 19.5 & & \\
\hline 3 & 21 & 22.6 & 39 & 47.6 & & \\
\hline
\end{tabular}

\subsection{Model of friendship network evolution and academic achievement}

The evolution models for 3 semesters are shown as table 4-6. The rate parameter describes the average number of changes in network ties between measurement points. The highest rate parameter is in the beginning of each semester. And it is higher between 2 semesters than during the semesters.

The endogenous network effects are all statistically significant. The density, reciprocity and transitive triplets have effects during all the stages. The negative density effect represents the hindrance of dissolved relationships. The reciprocity effect indicates a preference for reciprocating relationships. The transitivity effect indicates a preference for being friends with friends' friends.

The effect of gender similarity was significant during all waves. The positive parameter implies that actors prefer ties to others with same gender.
Table 4. Evolution model of wave 1 to 4

\begin{tabular}{|c|c|c|c|}
\hline Variable & $\stackrel{\mathrm{w1}-2}{\text { Estimate(se) }}$ & $\frac{\stackrel{\mathrm{w} 2-3}{\text { Estimate(se) }}}{}$ & 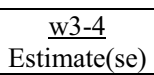 \\
\hline Rate parameter & $7.06(0.24)$ & $5.37(0.23)$ & $5.52(0.23)$ \\
\hline \multicolumn{4}{|l|}{ Network effects } \\
\hline Density & $-2.022(0.06)^{*}$ & $-1.88(0.06)^{*}$ & $-2.19(0.07)^{*}$ \\
\hline Reciprocity & $0.93(0.09)^{*}$ & $1.20(0.10)^{*}$ & $1.34(0.10)^{*}$ \\
\hline $\begin{array}{l}\text { Transitive } \\
\text { triplets }\end{array}$ & $0.11(0.01)^{*}$ & $0.13(0.01)^{*}$ & $0.11(0.01)^{*}$ \\
\hline Gender similarity & $0.37(0.08)^{*}$ & $0.40(0.09)^{*}$ & $0.42(0.09)^{*}$ \\
\hline \multicolumn{4}{|c|}{ Academic achievement similarity } \\
\hline Computer science & $0.03(0.10)$ & $0.29(0.12)^{*}$ & $-0.01(0.11)$ \\
\hline Mathematics & $0.10(0.09)$ & $-0.02(0.10)$ & $-0.03(0.11)$ \\
\hline Chinese & $-0.08(0.09)$ & $-0.08(0.10)$ & $0.19(0.11)$ \\
\hline English & $-0.18(0.09)$ & $-0.191(0.10)$ & $0.02(0.11)$ \\
\hline
\end{tabular}
$* \mathrm{p}<.05$

Table 5. Evolution model of wave 4 to 7

\begin{tabular}{|c|c|c|c|}
\hline Variable & $\frac{\underline{w 4-5}}{\text { Estimate(se) }}$ & $\frac{\mathrm{w} 5-6}{\text { Estimate(se) }}$ & $\frac{\mathrm{w} 6-7}{\text { Estimate(se) }}$ \\
\hline Rate parameter & $5.90(0.26)$ & $5.70(0.28)$ & $6.19(0.29)$ \\
\hline \multicolumn{4}{|l|}{ Network effects } \\
\hline Density & $-2.03(0.07)^{*}$ & $-2.10(0.06)^{*}$ & $-1.89(0.06)^{*}$ \\
\hline Reciprocity & $1.08(0.09)^{*}$ & $1.37(0.10)^{*}$ & $1.13(0.10)^{*}$ \\
\hline $\begin{array}{l}\text { Transitive } \\
\text { triplets }\end{array}$ & $0.16(0.01)^{*}$ & $0.13(0.01)^{*}$ & $0.14(0.01)^{*}$ \\
\hline Gender similarity & $0.61(0.09)^{*}$ & $0.37(0.09)^{*}$ & $0.50(0.08)^{*}$ \\
\hline \multicolumn{4}{|c|}{ Academic achievement similarity } \\
\hline Computer science & $0.040(0.11)$ & $-0.06(0.12)$ & $0.08(0.11)$ \\
\hline Mathematics & $0.34(0.10)^{*}$ & $-0.11(0.11)$ & $\begin{array}{l}-0.14(0.09) \\
\end{array}$ \\
\hline Chinese & $-0.07(0.10)$ & $-0.20(0.11)$ & $-0.03(0.11)$ \\
\hline English & $0.24(0.10)^{*}$ & $-0.06(0.12)$ & $0.11(0.10)$ \\
\hline
\end{tabular}

$$
* \mathrm{p}<.05
$$

Table 6. Evolution model of wave 7 to 10

\begin{tabular}{|c|c|c|c|}
\hline Variable & $\frac{\mathrm{w} 7-8}{\text { Estimate(se) }}$ & $\frac{\underline{w 8-9}}{\text { Estimate(se) }}$ & $\frac{\underline{w 9-10}}{\text { Estimate(se) }}$ \\
\hline Rate parameter & $6.50(0.30)$ & $6.60(0.34)$ & $4.99(0.24)$ \\
\hline \multicolumn{4}{|l|}{ Network effects } \\
\hline Density & $-2.17(0.07)^{*}$ & $-1.96(0.06)^{*}$ & $-1.89(0.07)^{*}$ \\
\hline Reciprocity & $1.51(0.10)^{*}$ & $1.34(0.09)^{*}$ & $1.13(0.10)^{*}$ \\
\hline $\begin{array}{l}\text { Transitive } \\
\text { triplets }\end{array}$ & $0.14(0.01)^{*}$ & $0.13(0.01)^{*}$ & $0.13(0.01)^{*}$ \\
\hline Gender similarity & $0.28(0.09)^{*}$ & $0.476(0.09)^{*}$ & $0.59(0.09)^{*}$ \\
\hline \multicolumn{4}{|c|}{ Academic achievement similarity } \\
\hline Computer science & $0.14(0.12)$ & $0.13(0.11)$ & $0.21(0.12)$ \\
\hline Mathematics & $0.06(0.11)$ & $-0.16(0.10)$ & $0.13(0.10)$ \\
\hline Chinese & $-0.11(0.11)$ & $-0.11(0.10)$ & $0.25(0.12)^{*}$ \\
\hline English & $0.06(0.11)$ & $0.17(0.10)$ & $0.09(0.10)$ \\
\hline
\end{tabular}

During wave 1 to wave 10 , the homophily effect of perceived academic achievement was significant for computer science at w2-3 stage, for mathematics and English at w4-5, and for Chinese at w9-10. The positive parameter indicates the tendency to be friends with the same perceived performance of academic achievement.

\section{Discussion and conclusion}

Consistent with previous studies, the similarity of academic achievement has effect on friendship network evolution. Longitudinal network data can yield important insights into social processes. Ten waves' observations may offer rich materials for understanding adolescents' 
friendship network development and its relationship with academic performance.

\subsection{Homophily effect of academic achievement}

Our findings revealed that the similarity effect of perceived achievement of computer science was significant during the first semester, the effects of mathematics and English were significant during the second semester, and the effect of Chinese was significant during the last semester.

Whether the achievement of academic is visible or invisible depends on social context and social norms. If most of them have good performance, the achievement would be visible. Otherwise, it would be invisible. About $70 \%$ of the participants were perceived themselves not worse than others for the achievements of computer science. The perceived achievement of computer science might be visible and has homophily effect in the first semester. The other reason may be due to the learning context. The computer science must learn by practicing on the computer. All the students learn in a computer classroom together. The learning process is visible. They can perceive others' achievement immediately and the perceived performance of computer science had homophily effect in the first semester.

During w4-5, the similarity effects of perceived performance are significant for the subjects of mathematics and English. W4 is the end of the first semester, and w5 is the beginning of the second semester. After a semester, the performances of these 2 subjects became visible and exert homophily effect.

Social comparison theory [4] suggests the drive to make comparisons with others who are more similar. The measurement of perceived performance is the result of comparison with others. Since people prefer to compare with others who are more similar, the comparison result of "worse than others" is not their favorable outcome. The unfavorable result of comparison will produce tendencies to change one's evaluation of the ability or lead to action for reducing the discrepancy and so as to move closer to others in the groups. Namely, the drive to have a favorable comparison result may trigger their behaviors by observing and imitating proposed by social learning theory. The students who perceived themselves better than others in Chinese and English have increasing tendency. It may be explained by this mechanism. The students will imitate others to modify their behavior for improving their performance.

The perceived performance of Chinese had effect in the last stage. Chinese is the native language of the participants. The comparison with others in this subject seems ridiculous or meaningless. This subject may be invisible or be ignored. It might be the reason why the homophily effect existed in the last stage.

Based on the hypothesis of van Duijn et al. [10], in early stage, visible similarity plays important role to initiate friendship, and in later stages, dyadic relations will be strengthened by invisible similarities. Since the achievement of computer science can be easily observed, the similarity effect of computer science exerts in early stage. The performances of other 3 subjects need more time to be observed and become visible and exert effect at later stages.

\subsection{Evolution of friendship networks and gender effect}

The rate parameter is up and down, then decreasing at the end of observation. It represents the friendship network is dynamic but not steady. The effects of network are the same as the results of van Duijn et al. [10]. Network density, transitive triplets, and reciprocity are important for friendship evolution during all stages. These three factors are the most important effects for the structural part of the model for network dynamics [14]. The density effect and the reciprocity effect must always be included in the dynamic model. There are four network closure effects. And it will be sufficient to express the tendency to network closure by including at least one factor. The transitive triplet effect is selected to be included in the model. It is the representation of network closure by the number of transitive triplets. For this effect the contribution of the tie $i \rightarrow j$ is proportional to the total number of transitive triplets that it forms which can be transitive triplets of the type $\{i \rightarrow j \rightarrow h ; i \rightarrow h\}$ as well as $\{i \rightarrow h \rightarrow j ; i \rightarrow j\}$.

In our findings, positive parameter of gender similarity indicated the tendency of preference to make same-sex friends. Gender is a visible variable and exerts effect in the beginning of friendship formation. After initiation of friendship, gender keeps its effect during all the waves. Obviously, gender is a powerful organizer of peer relationships throughout development. Adolescents report feeling closer to their same-sex friends than to their other-sex friends $[15,16]$. Thus, same-sex friendships are an important resource for the development of social health during adolescence. However, heterosex friendships represent unique opportunities both for healthy development and adverse development [17]. Other-sex friendships may aid youth in learning how to interact productively with individuals with interests, experiences, and backgrounds that differ from their own.

\subsection{Gender difference of academic performance}

Our findings are consistent with most of the previous studies. The results revealed gender difference of perceived performance for mathematics, Chinese and English, but not computer science.

Falaye [18] indicated that academic achievement gap pertaining to gender exists based on subject. Most studies found a positive gender gap in language art; and a traditional negative gap in STEM (science, technology, engineering, and mathematics). O'Reilly and McNamera [19] investigated the performance of high school students and found significant gender differences with males scoring higher on measures of passage comprehension and science knowledge and females 
scoring higher on measures of reading skills, strategy knowledge, and those pertaining to course grades. Preckel et al. [20] indicated that male students can obtain higher grades in mathematics whereas female students are better in oral skills. Gong, Ding, and Tsang [21] estimated gender gaps in Chinese and math among primary and lower-secondary school students and found small positive gaps favoring girls in Chinese and negative gaps in math for all grades. Jansen, Schroeders, and Ludtke [22] analyzed data and found that female students possess a lower self-concept in chemistry and physics.

The gender difference may come from psychological factors. Ghazvini, and Khajehpour [23] found that the girls take greater responsibility for academic failures and it is associated with the girls' obtaining better results in the subject of Literature. The same research also reveal that boys use concentration, information processing and selecting main ideas strategies more, and getting better marks in mathematics. Furthermore, Sinclair, Carlsson \& Bjorklund [24] suggested social networks are of importance for gender differences in field of study and the differences is rooted in the tendency for adolescents to form same-gender friendships. Female adolescents who adjust their choice in line with friends will be more likely to choose a female-dominated field of study.

\subsection{Conclusion}

In conclusion, social network analysis is uniquely suited for measuring and understanding the behavior of peers because it provides a formal means for "mapping" friendships and measuring properties of those friendships [25]. Friendship network is initiated by chance; in the early stages the proximity and visible similarity variables determined dyadic relations. In later stages, dyadic relations will be strengthened by invisible similarities. Our findings of homophily effects for different subjects in different stages offered some evidence to support this argument.

\section{References}

1. J.M. McPherson, L. Smith-Lovin, J.M. Cook, Birds of a feather: homophily in social networks. Annu. Rev. Sociol. 27, 415-444 (2001)

2. N. Friedkin, Norm formation in social influence networks. Soc. Networks. 23, 167-189 (2001)

3. E.R. Oetting, J.F. Donnermeyer, Primary socialization theory: the etiology of drug use and deviance. Subst. Use. Misuse. 33, 995-1026 (1998)

4. L. Festinger, A theory of social comparison processes. Human Relations 7, 117-140 (1954)

5. A. Bandura, Social Learning Theory. Prentice Hall, Englewood Cliffs, N.J. (1977)

6. J. Daw, G. Guo, K.M. Harris, Nurture net of nature: Re-evaluating the role of shared environments in academic achievement and verbal intelligence. Social Science Research 52, $422-439$ (2015)

7. I. Levy-Tossman, A. Kaplan, A. Assor, Academic goal orientations, multiple goal profiles, and friendship intimacy among early adolescents 32, 231-252 (2007)

8. K.A. Frank, C. Muller, K.S. Schiller, C. RiegleCrumb, A.S. Mueller, R. Crosnoe, J. Pearon, The social dynamics of mathematics coursetaking in high school, AJS 113(6), 1645-1696 (2008)

9. S. Hasan, S. Bagde, The mechanics of social capital and academic performance in an Indian college, American Sociological Review 78(6), 1009-1032 (2013)

10. M.A.J. van Duijn, E.P.H. Zeggelink, M. Huisman, F.N. Stokman, F.W. Wasseur, Evolution of sociology freshmen into a friendship network, Journal of Mathematiscal Sociology 27, 153-191 (2003)

11. T.A.B. Snijders, Stochastic Actor-oriented Models for Network Change, Journal of Mathematical Sociology 21, 149-172 (1996)

12. T.A.B. Snijders, The Statistical Evaluation of Social Network Dynamics. In M.E. Sobel \& M.P. Becker (eds), Sociological Methodology, Boston: Basil Blackwell (2001)

13. R. Veenstra, C. Steglich, Actor-based model for network and behavior dynamics: A tool to examine selection and influence processes. Chapter 34 (pp. 598-618) in B. Laursen, T. D. Little, and N. A. Card (Eds.), Handbook of Developmental Research Methods. New York: Guilford Press (2012)

14. T.A.B. Snijders, C. Steglich, M. Schweinberger, M. Huisman, Manual for SIENA version 3, University of Groningen: ICS. Oxford: University of Oxfor, Department of Statistics. http://stat.gamma.rug.nl/stocnet (2007)

15. W. Bukowski, L. Sippola, B. Hoza, Same and other: Interdependency between participation in same- and other-sex friendships, Journal of Youth and Adolescence 28, 439-459 (1999)

16. B. Lundy, T. Field, C. McBride, T. Field, S. Largie, Same-sex and opposite-sex best friend interactions among high school juniors and seniors, Adolescence 33, 279-289 (1998)

17. L.K. Sippola, Getting to know the "other": the characteristics and developmental significance of other-sex relationships in adolescence, Journal of Youth and Adolescence 28, 407-418 (1999)

18. F.V. Falaye, Numerical ability, course of study and gender differences in students' achievement in practical geography, Research in Education, 76, 3342 (2006)

19. T. O'Reilly, D.S. McNamera, The impact of science knowledge, reading skill, and reading strategy knowledge on more traditional "High-Stakes" measures of high school students' science achievement, American Educational Research Journal 44, 161-196 (2007)

20. F. Preckel, , T. Goetz, , R. Pekrun, \& M. Kleine, Gender differences in gifted and average-ability students: Comparing girls' and boy's achievement, self-concept, interest, and motivation in Mathematics, The Gifted Child Quarterly 52, 146160 (2008) 
21. X. Gong, Y. Ding, M.C. Tsang, Gender differences of academic performance in compulsory education in rural Southwestern China, International Journal of Educational development 39, 203-214 (2014)

22. M. Jansen, U. Schroeders, O. Ludtke, Academic self-concept in science: Multidimensionality, relations to achievement measures, and gender differences, Learning and Individual Differences 30, 11-21 ( 2014)

23. S.D. Ghazvini, M. Khajehpour, Gender differences in factors affecting academic performance of high school students, Procedia Social and Behavioral Sciences 15, 1040-1045 (2011)

24. S. Sinclair, R. Carlsson, F. Bjorklund, The role of friends in career compromise: same-gender friendship intensifies gender differences in educational choice, Journal of Vocational Behavior 84, 109-118 (2014)

25. S.T. Ennett, K.E. Bauman, Adolescent social networks: school, demographic, and longitudinal consideration, Journal of Adolescent Research 11(2), 194-215 (1996) 